\title{
DEVELOPMENT OF GRAVITY TYPE FRUIT SORTER
}

\author{
S. K. Rupnar ${ }^{1}$, R. T. Jadhav ${ }^{2}$, A. K. Rupnar ${ }^{3}$ \\ ${ }^{1}$ M.Tech. Scholar, CAET, Dr.BSKKV, Dapoli 415712 (Maharashtra) \\ ${ }^{2}$ Principal, Dr.BMCAET, Chiplun 415641 (Maharashtra) \\ ${ }^{3}$ Research Scholar, CTAE, MPUAT, Udaipur 313001 (Rajasthan)
}

\begin{abstract}
Sorting of fruits and vegetables is one of the important post-harvest operation. Sorting is necessary step in marketing and processing of fruits as it fetches high price to the grower and improves packaging and handling losses during transportation. So keeping this all in mind manually operated gravity type fruit sorter was developed for small scale grading operation. The developed hand operated sorter was comprised of hopper, grading channel, and collecting unit. The developed sorter was evaluated for Tomato sorting as per standard test code. During actual testing the samples were collected from different grades at particular interval of time and analysis of these collected samples were carried out for determination of various parameters such as grading error, cutting damage, skinning damage and output capacity. The average grading efficiency was found to be $79.2 \%$. The overall performance of developed hand operated fruit sorter was found to be satisfactory for sorting of Tomato fruits and it can utilized for sorting of variety of other fruits. The total cost of sorter was Rs.810 whereas an operational cost was about Rs.56/h.
\end{abstract}

Keywords: Fruit Sorter, Design, Testing, Hand Operated, Sorting Etc. ****

\section{INTRODUCTION}

India's diverse climate ensures availability of all varieties of fresh fruits \& vegetables. It ranks second in fruits and vegetables production in the world, after China. As per national horticulture database published by National Horticulture Board (NHB), during 2014-15 India produced 86.602 million metric tons of fruits and 169.478 million metric tons of vegetables. Sorting and Grading of fruits is a very important operation as it fetches high price to the grower and improves packaging, handling and brings an overall improvement in marketing system. The fruits are generally separated and graded on basis of size and graded fruits are more welcome in export market. Sorting could reduce handling losses during transportation. In India mostly fruit growers separate and grade fruits manually. Manual sorting of fruits is carried out by trained operators by considering numerous factors and fruit are separated according to their physical quality. Manually sorting is tedious, costly and the operation may be highly affected due to shortage of labor in peak seasons. Human operations may be inconsistent, less efficient and time consuming. In recent years, some of the progressive farmers have started using high capacity graders like mechanical grader, electronic size and color grader, screen grade etc. But these machines are always associated with the problems like complexity of operation, high initial, operating and maintenance cost. Also these machines are beyond the approach of an ordinary farmer as it is not flexible to acquire these machines. The available fruit sorters separate the fruits on the basis of color, shape and other physical or chemical properties. The graders or sorters available with color as grading parameters are always associated with use of high cost computers, sensors and hence have high initial cost and operating cost and such machines are best suited for large scale industrial application and not for small and marginal farmers.
To overcome these problems need was felt to develop manually operated gravity type fruit sorter which will sort out round and oblong fruits on the basis of size i.e., diameter. The machine must be simple in operation which will give higher capacity and will be portable. It will be also kept in mind that machine should be affordable by small and marginal growers and the operational and maintenance cost should be minimum. Machine could be constructed by local available material and should be operated by unskilled and semiskilled person also.

\section{DESIGN AND DEVELOPMENT OF SORTER}

A gravity type fruit sorter was developed for its three main functional components viz. hopper, grading channel and collector. These components were designed on the basis of theoretical considerations and a fruit sorter was developed comprising these three components as one unit. The performance evaluation of developed gravity type fruit sorter was carried out with Tomato fruit as per standard procedure for its different parameters namely

\subsection{Design of Hopper}

The hopper was designed for its volume and there by the sides i.e. top side and bottom side of hopper. The volume of hopper was fixed as $10000 \mathrm{~cm}^{3}$ as the storage capacity. The shape of the hopper was considered as trapezoidal with square sections at top and bottom side of hopper. Also the bottom width and breadth were considered as $12 \mathrm{~cm} \times 12 \mathrm{~cm}$ for easy passing of fruits from hopper to the grading unit. Then the hopper was designed for its width and breadth at the top. 
2.1.1 Volume of hopper box is given by, $\left(\mathrm{cm}^{3}\right)$

$$
\mathrm{V}_{\mathrm{b}}=1.1 \times \mathrm{V}_{\mathrm{f}}
$$

\subsubsection{Volume of fruit $\left(\mathrm{cm}^{3}\right)$}

$$
\mathrm{V}_{\mathrm{f}}=\mathrm{W}_{\mathrm{f}} / \gamma_{\mathrm{f}}
$$

\subsubsection{Total volume hopper box}

The box is assumed as square then, $a$ and $b$ are assume and $\theta=23^{\circ}-25^{\circ}$

$$
\mathrm{V}_{\mathrm{b}}=\mathrm{V}_{\mathrm{A}}+\mathrm{V}_{\mathrm{B}}
$$

Where,

$\mathrm{V}_{\mathrm{b}}=$ Volume of fruit box

$\mathrm{V}_{\mathrm{A}}=$ Volume of section $\mathrm{A}$ of box

$\mathrm{V}_{\mathrm{B}}=$ Volume of section $\mathrm{B}$ of box

$$
\mathrm{V}_{\mathrm{A}}=l \times b \times t
$$

And

$$
\mathrm{V}_{\mathrm{B}}=1 / 2(2 a+2 l) \times h_{2} \times \mathrm{b}
$$

Considering this value of bottom side hopper was to be taken for designing of hopper.

Thehopper box was prepared by assuming parameter as $\mathrm{a}=12 \mathrm{~cm}, \mathrm{~h}_{1}=9 \mathrm{~cm}, \mathrm{~h}_{2}=20 \mathrm{~cm}, \mathrm{~b}=20 \mathrm{~cm}, l=4 \mathrm{~cm}$

$\mathrm{V}_{\mathrm{A}}=\mathrm{b} \times \mathrm{b} \times \mathrm{h}_{1}$

$\mathrm{V}_{\mathrm{B}}=1 / 2(2 \mathrm{a}+2 l) \times \mathrm{h}_{2} \times \mathrm{b}$

Since, the desired volume of fruit box is $10000 \mathrm{cu} . \mathrm{cm}$. which is higher than theoretically calculated volume (9467.79 cu. cm.) therefore, designed dimension of the box are correct.

\subsection{Grading Unit}

It is the main and important unit of sorter. The function of this unit is to grade the fruits those are fed from hopper. The sorting unit consisted of four spirals, having slope of $20^{\circ}$.The spirals have holes of different diameter ranges from $2.5 \mathrm{~cm}$ to $17 \mathrm{~cm}$. There was narrow clearance kept between the shafts where the fruits are to be fed and sufficient slope is provided for the spiral so that by gravity, fruits could be rolled and graded efficiently. The spirals were made up of from 22 gauge sheet. For collecting unit cushioning material was provided so that fruits graded should not be damaged.

\subsection{Outlet/Collecting Unit}

The primary function of this unit is to collect the graded fruits from the grading unit in number of fractions /sizes according to necessity. For this purpose at least three grades of fruits were considered. The fabrication was accomplished by constructing metallic boxes and these boxes were placed below the grading unit. The mild steel sheet of 22 gauge was used for construction of collecting unit and collecting boxes.

There are different outlets designed as per the height of fruit drop, so that fruits cannot damaged. For protection of fruits there is some cushioning material provided. And the fruits sorted into the outlets are conveyed into different grades.

\section{RESULTS AND DISCUSSION}

The performance evaluation of developed gravity type fruit sorter was carried out with freshly harvested half ripe Tomato fruits. The developed sorter was tested and evaluated for its performance on the basis of grading efficiency, output capacity, percent of damaged fruits and skinned fruit etc.The sorting of Tomato fruits was done on the basis of size and graded in three grades viz. GI- Small, GII-Medium and GIII-Large with three different feed rate tests (T1, T2 and T3) as given in Table1.The size of Tomato fruits in respective grades is $\leq 4 \mathrm{~cm}$ for GI, $4-6 \mathrm{~cm}$ for GII and $6-8 \mathrm{~cm}$ for GIII. During the grading operation some fraction of Tomato fruits damaged due to bruising and cutting was also taken into account.

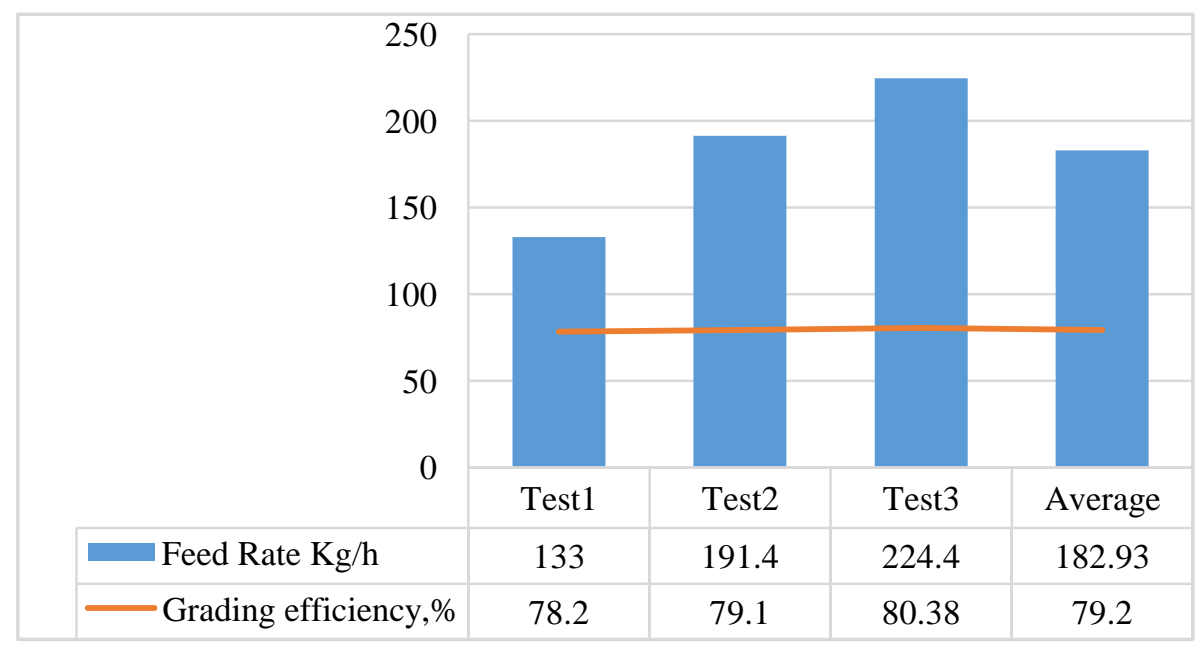

Fig-1: Efficiency of sorter for different tests 
The results obtained from evaluation of sorter with Tomato fruits showed that the feed rate was recorded to be 133 , 191.4 and $224.4 \mathrm{~kg} / \mathrm{h}$ for Test 1 , Test 2 and Test 3 respectively and the average feed rate was observed as $182.93 \mathrm{~kg} / \mathrm{h}$. It was also observed that feed rate was largely depend on the size of hopper as well as bulk density of Tomato fruit. The grading efficiency of sorter was obtained with the Tomato fruit was $78.2,79.1$ and $80.38 \%$ for Test 1 , Test 2 and Test 3 respectively. An average grading efficiency for fruit sorter was found to be $79.2 \%$. A slight variation in efficiency during three tests was observed because of different loading rates and manually loading of Tomato fruits. The grading efficiency is sensitive to feed rate and slope of the spiral chute (feed end to holes of respective grades). Therefore these two factors were considered for design of sorter for better grading efficiency. The average cutting damage value was found to be $0.667 \%$. This happened because of sharp edges of holes from which fruits drop into their respective grades. Though this value is small but must be eliminated for large scale operation to improve the grading efficiency. The bruising damage value by sorter to Tomato fruits was found to be zero. The average skinning damage was obtained to $1.1 \%$. This was observed due to the rolling of fruits along the metal surface of spiral chutes of grader. In all, the overall performance of gravity type fruit sorter was found satisfactory and sorter can be used for many other spherical and round fruits at farm level operation.

\section{COST ECONOMICS}

The total cost of fruit sorter was around Rs.810 including all the components viz. hopper, grading unit and collecting unit etc. Considering $12 \%$ salvage value, $15 \%$ interest rate, $10 \%$ repairs and maintenance charges, $2 \%$ insurance and taxes, $1.5 \%$ housing for effective life of sorter in 10 years, the operational cost of sorter was determined as Rs.56 per hour for sorting of Tomato fruits. Therefore the cost of sorter was found affordable for small farmers that it can be easily operated by only one person.

\section{CONCLUSION}

A gravity type fruit sorter was developed for small scale operation that a farmer can easily grade fruits at farm level. This sorter is suitable for many types of spherical and round shape fruits. Being a gravity type there is no need of any external power source to sort out fruits. The grading efficiency of sorter was found to be $79.2 \%$ which denotes it is more efficient way for grading fruits rather than manual operation. The cost of sorter was around Rs.810 therefore it is affordable for poor farmers also.

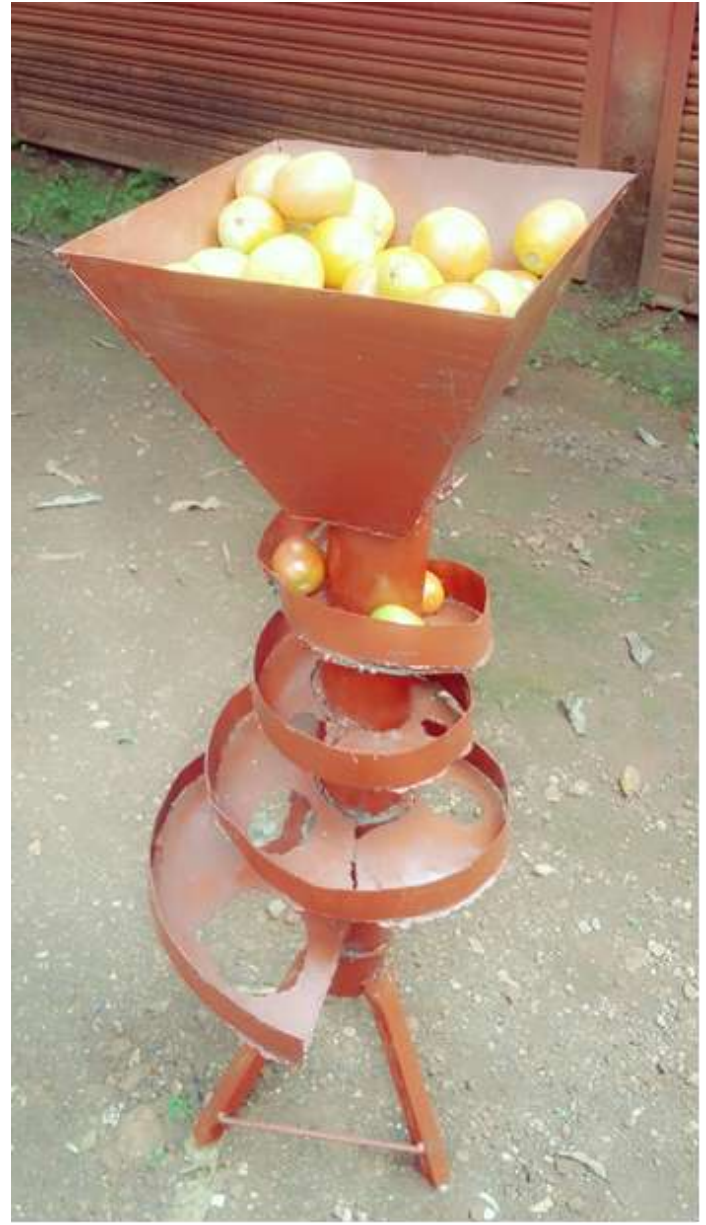

Fig-2: Sorting of tomatoes with the help of gravity type fruit sorter

\section{REFERENCES}

[1]. Anuradha P. (2014) Implementation of fruit Grading System by Image Processing and Data Classifier- A Review pp 411-413

[2]. Borkar .P.A (2013). Testing the performance of spherical fruit grader for apple and pomegranate, All India Coordinated Research Project on Post-Harvest Technology Dr. Panjabrao Deshmukh Krishi Vidyapeeth, Akola. International Journal of Science, Environment , Technology, 2(5):1059-1071

[3]. Londhe D. S. Nalawade, G. Pawar, V. Atkari, and S.Wandkar. (2013). Grader: A review of different methods of grading for fruits and vegetables. Agric Eng Int: CIGR Journal, 15(3):217-230

[4]. Anonymous (2011) Database of National Horticulture Board, Ministry of Agriculture Govt. of India. pp

[5]. Khojastehnazhand M, M. and A.Tabatabaeefar (2010).Development of a lemon sorting system based on colour and size. African Journal of Plant Science 4(4):122127.

[6]. Ukey P.D. and P. A. Unde (2009). Design and development of sapota grader. International Journal of Agricultural Engg.. 3(1):35-49.

[7]. Ashraf M, M., S. Sabir, M. Ahmed and M. Yasin (2007). Design, development and performance evaluation of 
fruit and vegetable grader. Pak. J. of Agri. Sci., 44(4):704-

713.

[8]. Rao S.P. and S. Rangnathan (2002). New approaches for Size determination of apple fruits for automatic sorting and grading. Iranian Journal of Electrical and Computer Engg.1 (2), 90-97.

[9]. Houston R. K, S. Clara, J. Meador, and S. Valley (1981).Apparatus for sorting fruits according to colour. Specification United State Patent, Patent no. 4281933, page no. 1-12. 